\title{
Measuring Tumor Necrosis Factor-Alpha and Interleukin-1 Beta Levels in Mustard Gas Exposed Patients
}

\author{
Hoda Sheibani ${ }^{1}$, Mohammad Goudarzi ${ }^{2}$, Malek Ashtar Esfandiari ${ }^{3 *}$, Fatemeh Rousta ${ }^{4}$, \\ Reza Haji Hosseini ${ }^{5}$
}

${ }^{1}$ Graduate of Biochemistry, Immunohematology Department, Blood Transfusion Center, High Institute for Research Center and Education in Transfiusion Medicine, Tehran, Iran

${ }^{2}$ Graduate of Biochemistry, Payame Noor University, Tehran, Iran

${ }^{3}$ Hygiene Department, Ministry of Education, Tehran, Iran

${ }^{4}$ Department of Microbiology, Islamic Azad University, Science and Research Branch, Tehran, Iran

${ }^{5}$ Department of Biochemistry, Payame Noor University, Tehran, Iran

Email: *Malek.esfandiari@gmail.com

How to cite this paper: Sheibani, H., Goudarzi, M., Esfandiari, M.A., Rousta, F. and Hosseini, R.H. (2017) Measuring Tumor Necrosis Factor-Alpha and Interleukin-1 Beta Levels in Mustard Gas Exposed Patients. Advances in Bioscience and Biotechnology, 8, 134-141.

https://doi.org/10.4236/abb.2017.84010

Received: February 26, 2017

Accepted: April 27, 2017

Published: April 30, 2017

Copyright $\odot 2017$ by authors and Scientific Research Publishing Inc. This work is licensed under the Creative Commons Attribution International License (CC BY 4.0).

http://creativecommons.org/licenses/by/4.0/

\begin{abstract}
Sulfur mustard (SM) is an alkalizing chemical which has been used mostly as a weapon all over the world. Sulfur mustard can cause damages to many organs, especially the skin, respiratory system and the eyes. Generally, many complications of mustard gas result from its alkalizing potency and reaction with cellular components like DNA, RNA, proteins and lipid membranes. The damages caused by SM will lead to many complications which persist during the lifespan of exposed subjects. Pro-inflammatory cytokines including especially TNF- $\alpha$ and IL- $1 \beta$ can cause systemic inflammatory reactions and vast changes like altered cell signaling, migration, cytokine production changes and fever. This study was designed to analyze cytokine levels in mustardgas-exposed people's serum in the war between Iraq and Iran, who had the chronic dry-eye symptoms compared to the normal group, 30 years after exposure. In this study, 25 veterans who were exposed to mustard gas were compared to 25 healthy people as control group. The veterans with concurrent involvement of eye, lung, and skin were selected. We used ELISA method to assess the levels of TNF- $\alpha$ and IL- $1 \beta$ in serum of people in both groups. All the results analyzed with T-test in SPSS 17 statistical software. The mean levels of TNF- $\alpha$ and IL- $1 \beta$ in serum of chemical exposed veterans were $52.3 \pm$ $1.4 \mathrm{pg} / \mathrm{ml}$ and $3.43 \pm 0.3 \mathrm{pg} / \mathrm{ml}$ while in the control group were $19.5 \pm 1.3$ $\mathrm{pg} / \mathrm{ml}$ and $2.25 \pm 0.2 \mathrm{pg} / \mathrm{ml}$, respectively. In the control group, the serum pro-inflammatory cytokine levels were significantly lower than the exposed group $(P<0.05)$. This study showed that there is a meaningful difference be-
\end{abstract}


tween TNF- $\alpha$ and IL-1 $\beta$ serum levels in the SM exposed group compared to the control group. There are some differences between the present study and others. However, studies on local inflammatory changes in these patients are also limited and need more reviews.

\section{Keywords}

Mustard Gas (SM), Cytokine, TNF- $\alpha$ and IL- $1 \beta$

\section{Introduction}

Sulfur mustard (SM) is a vesicant-type chemical warfare agent introduced in World War I and then it was vastly used in a number of wars. Sulfur mustard was used as a chemical warfare agent during the Iran-Iraq war between 1983 and 1988, and roughly 45,000 patients are now suffering from the late complications of sulfur mustard poisoning, with high morbidity [1] [2] [3]. Short and long term effects of SM in various organs of exposed people, especially the skin, eyes and respiratory tract are reported [4] [5] [6] [7]. The damaging mechanisms are not clearly understood [8] [9]. Considering the importance of inflammatory cytokines in many delayed complications of skin and lung injuries [10] [11] [12], this study has focused on the serum concentrations of the most important inflammatory cytokines including TNF- $\alpha$ and IL- $1 \beta$. Inflammatory cytokines such as TNF and IL-1 have an important role in coordinating defense response to inflammation through interaction with their receptors.

Tumor necrosis factor (TNF) is an important inflammatory cytokine in both acute and chronic inflammations which causes an inflammatory response through interaction with its receptors expressed on various cells like endothelial cells. This cytokine increases vascular permeability allowing leukocyte access to the site of infection. Furthermore, in the case of local inflammatory response, systemic release of TNF may lead to septic shock and death [13]. Interleukin-1 (IL-1) and TNF have many close related activities, although they have distinct structure and bind to different receptors. IL-1 has two structural types; IL-1 $\alpha$ and IL- $1 \beta$, which bind to two different receptors in target cells. Receptor type I acts in signaling and type II performs as decoy and soluble forms of receptors. IL-1 is produced by different cell types like macrophage monocyte linage, epithelial cells and keratinocytes. IL-1 is produced during inflammation, injury, immunological challenge or infection and leads to inflammatory response which may affect both acute and chronic diseases [14] [15]. IL-1 nearly affects on every cell type, often in concert with other cytokines or other mediators and plays a role in development of disease and also in normal homeostasis [16] [17]. Its role includes normal metabolism, hematopoiesis, renal and hepatic function, regulation of blood pressure, sleep, ACTH release and increased sodium excretion [14] [15]. The aim of this study is to monitor the inflammatory cytokines; TNF- $\alpha$ and IL- $1 \beta$, in serum samples of the SM-exposed subjects, 30 years after exposure 
by ELISA method in comparison with control group.

\section{Materials and Methods}

This study was conducted in Baqiyatallah hospital, Tehran, Iran, in 2012. Ethical approval was sought and approved by the Ethical Committee of the Faculty/Institute Research Committee, Payame Noor University. Our community contains 50 men including two groups; group 1 containing 25 healthy subjects as normal group (Mean age $52.94 \pm 3.31$ ) and group 2 includes 25 patients who were last exposed at least 30 years ago as patient group patients (Mean age 52.27 \pm 3.37 ), with $\mathrm{P}>0.05$ between the ages of two groups. The shared inclusion criteria for all groups were: being male gender, having almost the same age range and availability for future evaluation. A questionnaire containing pulmonary symptoms (chronic cough, sputum, hemoptysis, and dyspnea), history of eye surgery(corneal transplants, closed tear duct), eye problems (Blepharitis, Dry eye), skin problems and medications used, was completed by specialist doctors for group two being a chemical exposed veteran who were last exposed at least 30 years ago.

\subsection{Serum Collection}

Blood samples were obtained from the antecubital vein at rest. Blood was drawn into Vacutainer tubes (BD Biosciences). The sera were separated by $20 \mathrm{~min}$ centrifugation at $2000 \times \mathrm{g}\left(4^{\circ} \mathrm{C}\right)$, aliquated, labeled and kept frozen at $-80^{\circ} \mathrm{C}$ until they were used for Enzyme-Linked Immunosorbent Assay (ELISA). Serum TNF$\alpha$ and IL- $1 \beta$ was measured by the Bender MedSystem Human TNF- $\alpha$ (BMS 223/4; Medical System Diagnostic GmbH, Austria, test sensitivity $2.3 \mathrm{pg} / \mathrm{mL}$ ) and Human IL-1 $\beta$ (BMS 224/2; Medical System Diagnostic GmbH, Austria, test sensitivity $0.3 \mathrm{pg} / \mathrm{mL})$.

\subsection{Assay Procedure}

All reagents and samples were brought to room temperature $\left(18^{\circ} \mathrm{C}\right.$ to $\left.25^{\circ} \mathrm{C}\right)$ before use. It is recommended that all standards and samples be run at least in duplicate. $100 \mu \mathrm{l}$ volume of each standard and sample and then $50 \mu \mathrm{l}$ of Biotin-Conjugate were added into appropriate wells. The wells were covered and incubated for 2 hours at room temperature on a micro-plate shaker set at 400 $\mathrm{rpm}$. The solution was discarded and washed 4 times with $1 \mathrm{x}$ wash solution. Washing was done by filling each well with washing buffer ( $400 \mu \mathrm{l})$, using a multi-channel pipette or auto-washer. Complete removal of liquid at each step is essential to good performance. After the last wash, any remaining wash buffer was removed by aspirating or decanting. The plate and blot were inverted against clean paper towels. After that, $100 \mu \mathrm{l}$ of diluted Streptavidin-HRP were added to all wells, including the blank wells, incubated for $1 \mathrm{~h}$ at room temperature with gentle shaking and the solution discarded. The washing process was repeated as in step 3. Later, $100 \mu \mathrm{l}$ of TMB Substrate Solution was added to all wells. The solution was incubated for $10 \mathrm{~min}$ at room temperature in the dark with gentle 
shaking. In the end, $100 \mu \mathrm{l}$ of stop solution was added to each well and read at $450 \mathrm{~nm}$ immediately.

\subsection{Statistical Analysis}

Statistical comparison among groups was performed using the T-test. Statistically significant value was defined as $\mathrm{p}<0.05$. Analysis of all data was performed with the SPSS 17.

\section{Results}

The mean level of TNF- $\alpha$ and IL- $1 \beta$ in serum of control group were $19.5 \pm 1.3$ $\mathrm{pg} / \mathrm{ml}$ and $2.25 \pm 0.2 \mathrm{pg} / \mathrm{ml}$, respectively; while in the chemical exposed veterans were $52.3 \pm 1.4 \mathrm{pg} / \mathrm{ml}$ and $3.43 \pm 0.3 \mathrm{pg} / \mathrm{ml}$, respectively. In the control group, the serum pro-inflammatory cytokine levels were significantly lower than the exposed group $(\mathrm{P}<0.05)($ Table 1$)$.

\section{Discussion}

Regarding the vital role of inflammatory cytokines in different organs damages, the aim of this study is to monitor the amount of serum TNF- $\alpha$ and IL- $1 \beta$, long term after SM exposure, in comparison to the control. We selected veterans with concurrent involvement of skin, lung and eyes. For most of immunity system diseases with delayed complications in skin, lung and eyes, although there are different mechanisms, inflammatory cytokines play very important roles. It has been reported that in patients with various infectious and non-infectious diseases, the production of inflammatory cytokine increases [18]. Also, this condition occurs in other chronic situations such as cystic fibrosis [19], Rheumatoid arthritis and atherosclerosis [18], pulmonary fibrosis, chronic osteomyelitis, and allergic asthma [11] [20] [21] [22]. IL-1 plays an important role in pathogenesis and maintenance of CNS diseases, such as multiple sclerosis, Alzheimer and clinical evolution of coronary artery diseases. In patients with congestive heart failure, it is strongly related to the severity of symptoms. IL- $1 \alpha$, IL- $1 \beta$, IL-1Ra are three members of the IL-1 gene family which have important roles. Relations have been shown for plasma IL-1 $\beta$ levels and the severity of acute attacks of Rheumatoid arthritis, thermal burns and mortality in septic shock [21]. TNF has also roles in chronic diseases such as pulmonary fibrosis, chronic osteomyelitis and allergic asthma [23]. In humans to treat Rheumatoid arthritis and Crohn's

Table 1 . The TNF- $\alpha$ and IL- $1 \beta$ mean-concentrations in serum.

\begin{tabular}{cccc}
\hline \multirow{2}{*}{ Groups } & $\mathrm{N}$ & \multicolumn{2}{c}{ Concentration $(\mathrm{pg} / \mathrm{ml})$} \\
\cline { 3 - 4 } & & $\mathrm{TNF}-\alpha$ & $\mathrm{IL}-1 \beta$ \\
\hline 1. Normal group & 25 & $19.5 \pm 1.3$ & $2.25 \pm 0.2$ \\
2. Chemically exposed & 25 & $52.3 \pm 1.4$ & $3.43 \pm 0.3$ \\
$\mathrm{P}^{*}$ (T- test) & & 0.00 & 0.001 \\
\hline
\end{tabular}

*comparing group 2 with 1. 
disease, anti-TNF antibodies have been employed [11]. There are several reports about the harmful effects of SM in various organs which show the early and late effects of just one exposure [8] [24]. Late cutaneous lesions of SM-exposed subjects include severe dry skin, hyper and hypopigmentation, local hair loss, Eczema and chronic urticaria. Moreover, higher incidence of vitiligo, psoriasis and discoid lupus erythematous has been reported in exposed patients [25] [26] [27]. Their effects on eyes mostly are reported in chronic phase. Ocular surface changes include Blepharitis, decreased tear, limbal ischemia, conjunctival vascular abnormalities, corneal scar or opacity, neovascularization, thinning, lipoid deposits, amyloid deposits and epithelial defects and irregularities [28]. There are few literatures about immunological status of SM-exposed subjects and the main questions are remained unanswered. Besides, the published literature about long term effects of SM on their immune system and the amount of cytokines are rare. The studies on short term effects showed that both cellular and humoral immune functions are impaired [8]. Some experimental models showed that shortly after SM exposure, cytokine production increases strongly [29] [30]. These reports are parallel to our findings that serum levels of TNF- $\alpha$ and IL- $1 \beta$ in exposed patients are meaningfully more than control group $(\mathrm{P}<0.05)$.

The study of Emad and Emad on the local inflammatory changes showed increased levels of TNF- $\alpha$ and IL- $1 \beta$ in the bronchoalveolar lavage of patients with bronchiectasis caused by SM gas inhalation compared to control group [31]. However, there are some contrasts between our study and Emad and Emad's. They have analyzed cytokines level in bronchoalveolar lavage (BAL) fluid of patients with pulmonary fibrosis (PF) [32]. In another study, Yaraee et al, showed the serum levels of TNF- $\alpha$ and IL- $1 \beta$ decreased meaningfully in SM exposed participants comparison to the control group [33]. They selected groups based on the SM exposure duration and possessing different clinical status, mostly at mild or moderate severity or normal criteria, but in our study all the subjects were in severe level. Furthermore, the inflammatory cytokines decrement can be related to several mechanisms such as negative feedback, especially by other cytokines in immune system which is one of the most important mechanisms. Known suppressors of TNF activity are cytokines such as IFN- $\alpha$, IFN- $\beta$, TGF- $\beta$, IL-4, IL-6, IL-10, IL-11, IL-13 and G-CSF. Moreover, serine proteases and caspases are TNF suppressor. Likely, the strongest inhibitor of TNF is the soluble form of the TNF receptor, is released from cell surface and block TNF activity. In addition, some cytokines are TNF inducer, such as, IFN- $\gamma$, IL-1, IL-2, GM-CSF, M-CSF and TNF itself [11] [34]. The endogenous inhibitors of IL- $1 \beta$ are TGF- $\beta$, IL-10, IFN- $\gamma$, IL-13, and members of the gp130 family (IL-6 and CNTF) [10]. Decrement or functional capacity deficiency of main sources of cytokines like macrophages or cascade signaling impairment may occur.

Survey on these cytokines to clarify the results can help. Results from this study suggest a potential role for cytokines increase in the incidence and severity of injuries and diseases of different organs. Despite this, this study is incomplete and requires further studies, such as evaluation of other cytokines or analyzing 
these factors in different samples like tear to help doctors treat patients.

\section{References}

[1] Mahmoudi, M., Hefazib, M., Rastina, M. and Balali Mood, M. (2005) Long-Term Hematological and Immunological Complications of Sulfur Mustard Poisoning in Iranian Veterans. International Immunopharmacology, 5, 1479-1485.

[2] Gosden, C.M. (2001) The 1988 Chemical Weapons Attack on Halabja, Iraq. In: Alexander, Y. and Hoening, M., Eds., Super Terrorism: Biological Weapons, Chemical and Nuclear, Transnational Publishers, Ardsley, NY, 7-12.

[3] Dacre, J.C. and Goldman, M. (1996) Toxicology and Pharmacology of the Chemical Warfare Agent Sulfur Mustard. Pharmacological Reviews, 48, 289-326.

[4] Maynard, R.L., Meredith, T.J., Marrs, T.C. and Vale, J.A. (1991) Management of War Injuries. The Lancet, 337, 122.

[5] Zandieh, T. (1991) Immunological Changes in Chemical Warfare Victims. First Congress of Biochemistry. Pastur Institute Press, Tehran.

[6] Dabrowska, M.I., Becks, L.L., Lell, J.L., et al. (1996) Sulfur Mustard Induces Apoptosis and Necrosis in Endothelial Cell. Toxicology and Applied Pharmacology, 141, 568-583. https://doi.org/10.1006/taap.1996.0324

[7] Sasser, L.B., Miller, R.A., Kalkwarf, D.R., et al. (1996) Subchronic Toxicity Evaluation of Sulfur Mustard in Rats. Journal of Applied Toxicology, 16, 5-13.

[8] Balali-Mood, M. and Hefazi, M. (2006) Comparison of Early and Late Toxic Effects of Sulfur Mustard in Iranian Veterans. Basic \& Clinical Pharmacology \& Toxicolo$g y, 99,273-282$. https://doi.org/10.1111/j.1742-7843.2006.pto_429.x

[9] Ghasemi, H., Ghazanfari, T., Yaraee, R., Soroush, M.R., et al. (2009) Systemic and Ocular Complications of Sulfur Mustard: A Panoramic Review. Toxin Reviews, 28, 14-23. https://doi.org/10.1080/15569540802689279

[10] Dinarello Charles, A. (2001) IL-1beta. In: Oppenheim, J.R. and Feldman, M., Eds., A Compendium of Cytokines and Other Mediators of Host Defense, Academic Press, Cambridge, MA.

[11] Bharat, B., Ajoy, S. and Feldmann, M. (2001) In: Oppenhelm, J.J. and Feldman, M., Eds., A Compendium of Cytokines and Other Mediators of Host Defense, Academic Press, Cambridge, MA.

[12] Balali-Mood, M., Hefazi, M., Mahmoudi, M., Jalali, I., et al. (2005) Long-Term Complications of Sulphur Mustard Poisoning in Severely Intoxicated Iranian Veterans. Fundamental \& Clinical Pharmacology, 19, 713-721. https://doi.org/10.1111/j.1472-8206.2005.00364.x

[13] Wajant, H., Pfizenmaier, K. and Scheurich, P. (2003) Tumor Necrosis Factor Signaling. Cell Death and Differentiation, 10, 45-56. https://doi.org/10.1038/sj.cdd.4401189

[14] Dinarello, C.A. (1997) Interleukin-1. Cytokine \& Growth Factor Reviews, 8, 253 265. https://doi.org/10.1016/S1359-6101(97)00023-3

[15] Subramaniam, S., Stansberg, C. and Cunningham, C. (2001) The Interleukin 1 Receptor Family. In: Oppenheim, J.R. and Feldman, M., Eds., A Compendium of $C y_{-}$ tokines and Other Mediators of Host Defense, Academic Press, Cambridge, MA.

[16] Dinarello, C.A. (2003) Interleukin-1 Family [IL-1F1, F2]. In: Thomson, A.W. and Lotze, M.T., Eds., The Cytokine Handbook, 4th Edition, Vol. I, Academic Press, Amsterdam, 643-668.

[17] Fitzgerald, K.A., O’Neill, L.A.J., Gearing, A.J.H. and Callard, R.E. (2001) The Cyto- 
kine Facts Book. 2nd Edition, Academic Press, London.

[18] Dinarello, C.A. (1996) Biologic Basis for Interleukin-1 in Disease. Blood, 87, 2095 2147.

[19] Cope, A.P. (1998) Regulation of Autoimmunity by Proinflammatory Cytokines. Current Opinion in Immunology, 10, 669-676.

[20] Montecucco, F. and Mach, F. (2009) Common Inflammatory Mediators Orchestrate Pathophysiological Processes in Rheumatoid Arthritis and Atherosclerosis. Rheumatology, 48, 11-22.

[21] Andreakos, E.T., Foxwell, B.M., Brennan, F.M., Maini, R.N. and Feldmann, M. (2002) Cytokines and Anti-Cytokine Biologicals in Autoimmunity: Present and Future. Cytokine \& Growth Factor Reviews, 13, 299-313. https://doi.org/10.1016/S1359-6101(02)00018-7

[22] Schreiber, S., Heinig, T., Panzer, U., Reinking, R., Bouchard, A., Stahl, P.D. and Raedler, A. (1995) Impaired Response of Activated Mononuclear Phagocytes to Interleukin 4 in Inflammatory Bowel Disease. Gastroenterology, 108, 21-33. https://doi.org/10.1016/0016-5085(95)90004-7

[23] Clark, I.A. (2007) How TNF Was Recognized as a Key Mechanism of Disease. $C y$ tokine \& Growth Factor Reviews, 18, 335-343. https://doi.org/10.1016/j.cytogfr.2007.04.002

[24] Emad, A. and Rezaian, G.R. (1997) The Diversity of the Effects of Sulfur Mustard Gas Inhalation on Respiratory System 10 Years after a Single, Heavy Exposure. Chest, 112, 734-738.

[25] Fekri, A.R. and Janghorbani, M. (1992) Late Dermal Complications in Iranian Veterans. Proceedings of the Seminar on Late Complications of Chemical Warfare Agents in Iranian Veterans, Veteran Foundation, Tehran, 57-89.

[26] Ghanei, M. and Adibi, I. (2007) Clinical Review of Mustard Lung. IJMS, 32, 58-65.

[27] Pourfarzam, Sh., Ghazanfari, T., Merasizadeh, J. and Ghanei, M. (2009) Long-Term Pulmonary Complications in Sulfur Mustard Victims of Sardasht, Iran. Toxin Reviews, 28, 8-13.

[28] Ghasemi, H., Ghazanfari, T., Babaei, M., Sourosh, M.R., Yaraee, R., Ghasemi-Broumand, M., et al. (2008) Long-Term Ocular Complications of Sulfur Mustard in the Civilian Victims of Sardasht, Iran. Cutaneous and Ocular Toxicology, 27, 317-326. https://doi.org/10.1080/15569520802404382

[29] Ricketts, K.M., Santai, C.T., France, J.A., Graziosi, A.M., Doyel, T.D., Gazaway, M.Y. and Casillas, R.P. (2000) Inflammatory Cytokine Response in Sulfur Mustard-Exposed Mouse Skin. Journal of Applied Toxicology, 20, S73-S76. https://doi.org/10.1002/1099-1263(200012)20:1+<::AID-JAT685>3.0.CO;2-H

[30] Sabourin, C.L.K., Danne, M.M., Buxton, K.L., Casillas, R.P. and Schlager, J.J. (2002) Cytokine, Chemokine, and Matrix Metalloproteinase Response after Sulfur Mustard Injury to Weanling Pig Skin. Journal of Biochemical and Molecular Toxicology, 16, 263-272. https://doi.org/10.1002/jbt.10050

[31] Emad, A. and Emad, Y. (2007) CD4/CD8 Ratio and Cytokine Levels of the BAL Fluid in Patients with Bronchiectasis Caused by Sulfur Mustard Gas Inhalation. Journal of Inflammation, 4, 2.

[32] Emad, A. and Emad, Y. (2007) Levels of Cytokine in Bronchoalveolar Lavage (BAL) Fluid in Patients with Pulmonary Fibrosis Due to Sulfur Mustard Gas Inhalation. Journal of Interferon \& Cytokine Research, 27, 38-43.

[33] Yaraee, R., Ghazanfari, T., Ebtekar, M., Ardestani, S.K., Rezaei, A., et al. (2009) Alterations in Serum Levels of Inflammatory Cytokines (TNF, IL-1alpha, IL-1beta and 
IL-1Ra) 20 Years after Sulfur Mustard Exposure: Sardasht-Iran Cohort Study. International Immunopharmacology, 9, 1466-1470.

[34] Lin, J., Ziring, D., Desai, Sh., Kim, S., Wong, M., Korin, Y., Braun, J., Reed, E., Gjertson, D. and Raj Singh, R. (2008) TNF- $\alpha$ Blockade in Human Diseases: An Overview of Efficacy and Safety. Clinical Immunology, 126, 13-30.

https://doi.org/10.1016/j.clim.2007.08.012

Submit or recommend next manuscript to SCIRP and we will provide best service for you:

Accepting pre-submission inquiries through Email, Facebook, LinkedIn, Twitter, etc. A wide selection of journals (inclusive of 9 subjects, more than 200 journals)

Providing 24-hour high-quality service

User-friendly online submission system

Fair and swift peer-review system

Efficient typesetting and proofreading procedure

Display of the result of downloads and visits, as well as the number of cited articles Maximum dissemination of your research work

Submit your manuscript at: http://papersubmission.scirp.org/

Or contact abb@scirp.org 